\title{
Developmental Changes in Structural and Functional Properties of Hippocampal AMPARs Parallels the Emergence of Deliberative Spatial Navigation in Juvenile Rats
}

\author{
Margaret G. Blair, ${ }^{\star}$ Nhu N.-Q. Nguyen, ${ }^{\star}$ Sarah H. Albani, Matthew M. L'Etoile, Marina M. Andrawis, Leanna M. Owen, \\ Rodrigo F. Oliveira, Matthew W. Johnson, Dianna L. Purvis, Erin M. Sanders, Emily T. Stoneham, Huaying Xu, \\ and Theodore C. Dumas \\ Molecular Neuroscience Department, Krasnow Institute for Advanced Study, George Mason University, Fairfax, Virginia 22030
}

The neural mechanisms that support the late postnatal development of spatial navigation are currently unknown. We investigated this in rats and found that an increase in the duration of AMPAR-mediated synaptic responses in the hippocampus was related to the emergence of spatial navigation. More specifically, spontaneous alternation rate, a behavioral indicator of hippocampal integrity, increased at the end of the third postnatal week in association with increases in AMPAR response duration at SC-CA1 synapses and synaptically driven postsynaptic discharge of CA1 pyramidal neurons. Pharmacological prolongation of glutamatergic synaptic transmission in juveniles increased the spontaneous alternation rate and CA1 postsynaptic discharge and reduced the threshold for the induction of activitydependent synaptic plasticity at SC-CA1 synapses. A decrease in GluA1 and increases in GluA3 subunit and transmembrane AMPAR regulatory protein (TARP) expression at the end of the third postnatal week provide a molecular explanation for the increase in AMPAR response duration and reduced efficacy of AMPAR modulators with increasing age. A shift in the composition of AMPARs and increased association with AMPAR protein complex accessory proteins at the end of the third postnatal week likely "turns on" the hippocampus by increasing AMPAR response duration and postsynaptic excitability and reducing the threshold for activitydependent synaptic potentiation.

\section{Introduction}

The hippocampus integrates multimodal sensory input to encode spatial memories (Morris et al., 2003; Stella and Treves, 2011) and develops late postnatally (Dumas, 2005a). Human children first express spatial memory at $\sim 2-3$ years of age (Huttenlocher, 2008), whereas rats display intact spatial navigation just after the end of the third postnatal week (Douglas et al., 1973; Green and Stanton, 1989; Rudy et al., 1987; Dumas, 2004). In rats, neurons in the hippocampus that encode self-location (place cells) are evident at $16 \mathrm{~d}$ of age (Langston et al., 2010; Wills et al., 2010), albeit they may be fewer in number and somewhat less

Received Oct. 11, 2012; revised June 5, 2013; accepted June 11, 2013.

Author contributions: L.M.O. and T.C.D. designed research; M.G.B., N.N.-Q.N., S.H.A., M.M.L., M.M.A., L.M.O., R.F.O., M.W.J., D.L.P., E.M.S., E.T.S., H.X., and T.C.D. performed research; M.G.B., N.N.-Q.N., D.L.P., H.X., and T.C.D. analyzed data; M.G.B., N.N.-Q.N., and T.C.D. wrote the paper.

This work was supported by the Thomas F. Jeffress and Kate Miller Jeffress Memorial Trust, the Department of Defense (Office of Naval Research Grant \#N00014-10-1-0198), and the Krasnow Institute for Advanced Study. AMPAKINEs were generously supplied by Cortex Pharmaceuticals. We thank Dr. Kim Blackwell for critical evaluation of the manuscript.

${ }^{*}$ M.G.B. and N.N.-Q.N. contributed equally to this work.

The authors declare no competing financial interests.

Correspondence should be addressed to Dr. Theodore C. Dumas, Molecular Neuroscience Department, Krasnow Institute for Advanced Study, George Mason University, 4400 University Drive, MS 2A1, Fairfax, VA 22030. E-mail: tdumas@gmu.edu.

DOI:10.1523/JNEUROSCI.4827-12.2013

Copyright $\odot 2013$ the authors $\quad 0270-6474 / 13 / 3312218-11 \$ 15.00 / 0$ stable than in adulthood (Scottet al., 2011). As shown by performance on various conditioning tasks, proximal (gustatory, olfactory, somatosensory) and distal sensory abilities (auditory, visual) are substantially mature by $18 \mathrm{~d}$ of age (Dumas, 2005b). Because spatial navigation reflective of normal hippocampal processing does not appear for almost another week, factors other than inadequate sensory input should also be considered when attempting to identify the physiological processes that regulate hippocampal maturation.

Prior electrophysiological findings implicate modifications in excitatory synaptic transmission in the maturation of hippocampal behaviors. Recordings from acutely prepared hippocampal slices have shown that, as early as 2 weeks of age, intrinsic membrane properties of hippocampal pyramidal neurons are not different from adults (Spigelman et al., 1992; Costa et al., 1994; Dumas and Foster, 1995; Hsia et al., 1998). In addition, in awake and behaving animals exploring a small arena, the average discharge rate did not change from $16 \mathrm{~d}$ of age to adulthood (Langston et al., 2010). These data suggest that changes in basic membrane properties and intrinsic excitability levels are not limiting factors in the final maturation of the hippocampus. Instead, measures of excitatory synaptic function (Dumas and Foster, 1995; Hsia et al., 1998; Hussain and Carpenter, 2001; Wang et al., 2002), postsynaptic excitation produced by activation of excit- 
atory synapses recorded in vitro (Harris and Teyler, 1983; Kudryashov and Kudryashov, 2001), and theta amplitude recorded in vivo (Wills et al., 2010) are altered at the age when hippocampal-dependent behaviors are first observed. These findings, along with direct investigation of postnatal development of the AMPAR protein complex (Ritter et al., 2002; Tomita et al., 2003; Fukaya et al., 2005), suggest functional alterations at excitatory synapses as limiting factors in the developmental emergence of spatial navigation. Therefore, we investigated the late postnatal development of excitatory synaptic transmission in relation to spatial navigation in rats. We found that a modification in the composition of the AMPAR protein complex and a resultant increase in the duration of AMPAR responses at SCCA1 synapses act to enhance postsynaptic excitability and reduce the threshold for activity-dependent synaptic plasticity, likely permitting the emergence of adult-like spatial navigation at the end of the third postnatal week.

\section{Materials and Methods}

Subjects. Male and female Long-Evans rats bred in the Krasnow Institute Animal Facility served as subjects for this study. Original and replacement breeders were purchased from Charles River Laboratories. Animals were maintained in individually ventilated cages (Animal Care Systems) on a 12:12 h light/dark cycle with lights coming on at 7:00 A.M. Water and food were available ad libitum. All procedures were performed in accordance with the regulations stated in the Guide for Care and Use of Laboratory Animals by the National Research Council and approved by the George Mason University institutional animal care and use committee.

Behavior testing. The Y-maze and elevated plus maze (EPM) tests were performed in a square room ( 12 by 12 feet) painted off-white with distinct spatial features (a stainless steel counter and cabinets across one wall, a dark gray door on an adjacent wall, and large black shapes applied to a third wall). The Y-maze (arm length: $26 \mathrm{~cm}$, arm width: $10 \mathrm{~cm}$, wall height: $12 \mathrm{~cm}$ ) was placed on the floor in the center of the room. The EPM (arm length: $40 \mathrm{~cm}$, arm width: $9 \mathrm{~cm}$, wall height: $15 \mathrm{~cm}$ ) was placed in the center of the room on a pedestal $(70 \mathrm{~cm}$ tall). The home cage containing the dam and entire litter was transported to the testing room $\sim 15$ min before testing. Animals to be tested were weighed, marked at the base of the tail with indelible ink, injected with drug (testing order was counterbalanced across doses), and placed back in the home cage for $30 \mathrm{~min}$. All subjects underwent one exposure to one maze. Each animal was placed in the center of the maze to start the test and allowed to freely explore for $8 \mathrm{~min}$. The mazes were wiped with $70 \%$ ethanol immediately after each run and allowed to dry before the subsequent test. CX614 and CX929 (kind gifts from Cortex Pharmaceuticals) were dissolved in cyclohexamide (Sigma-Aldrich). (-)-Bicuculline methiodide (BIC; Tocris Bioscience) was dissolved in PBS.

Electrophysiological recording. Methods for extracellular field recording in hippocampal slices have been described previously (Dumas, 2012). Briefly, slices were prepared in ice-chilled, oxygenated $\left(95 \% \mathrm{O}_{2}, 5 \%\right.$ $\mathrm{CO}_{2}$ ) artificial CSF (ACSF) containing the following (in $\mathrm{mM}$ ): $124 \mathrm{NaCl}$, $2 \mathrm{KCl}, 2 \mathrm{MgSO}_{4}, 2 \mathrm{CaCl}_{2}, 1.25 \mathrm{KH}_{2} \mathrm{PO}_{4}, 26 \mathrm{NaHCO}_{3}$, and 10 glucose, $\mathrm{pH}$ 7.4). Slices were perfused with oxygenated $\operatorname{ACSF}(1 \mathrm{ml} / \mathrm{min})$ and incubated at room temperature in a covered interface chamber for $2 \mathrm{~h}$ before recording. A bipolar Teflon-coated platinum-iridium simulating electrode was placed in stratum radiatum of area CA1 near the CA2 border. Population SC-CA1 synaptic responses and population discharge events were recorded with ACSF-filled glass microelectrodes (1-6 M $\Omega$ ) placed in area CA1 in the stratum radiatum and stratum pyramidale, respectively. Stimulation pulses (100 $\mu$ s duration) were varied in intensity to create input-output (I/O) curves for the fiber potential (FP), EPSP, and population spike (PS). For some experiments, pairs of stimulation pulses were applied and the interstimulus interval (ISI) was varied to assess paired-pulse facilitation (PPF) of the EPSP or paired-pulse inhibition (PPI) of the PS. BIC and CX614 were dissolved in DMSO. 2-Amino-5phosphonopentanoic acid (AP5) was dissolved in ACSF. Drug stocks were mixed at $1000 \times$ and diluted in ACSF just before use. For LTP experiments, the PS was set to a $1 \mathrm{mV}$ amplitude at baseline and EPSPs ranged between 0.5 and $1.5 \mathrm{mV}$. Files were discarded if the EPSP slope changed by $>10 \%$ during baseline or during drug application before induction stimulation. Signals were amplified $(100 \times)$ and band-pass filtered between 1 and $1000 \mathrm{~Hz}$ (AxoClamp 2B or MultiClamp; Molecular Devices) before being digitized at $10 \mathrm{kHz}$ (DigiData 1200 or $1440 \mathrm{~A}$ Series A/D interface; Molecular Devices). Experimental protocols were executed using pClamp (Molecular Devices).

For intracellular recording, animals were anesthetized (isoflurane vapor in a bell jar) and decapitated. Whole brain was quickly removed and immersed in ice-cold ACSF slicing solution containing the following (in mm): $125 \mathrm{NaCl}, 2.8 \mathrm{KCl}, 7 \mathrm{MgSO}_{4}, 1.25 \mathrm{NaH}_{2} \mathrm{PO}_{4}, 26 \mathrm{NaHCO}_{3}, 0.5$ $\mathrm{CaCl}_{2}, 10$ D-glucose, and 120 sucrose. Transverse brain/hippocampal slices $(450 \mu \mathrm{m})$ were cut with a vibratome in ice-cold slicing solution equilibrated with $95 \% \mathrm{O}_{2}$ and $5 \% \mathrm{CO}_{2}$. Slices were incubated for $1 \mathrm{~h}$ at $32^{\circ} \mathrm{C}$ in oxygenated ACSF containing the following (in $\mathrm{mm}$ ): $125 \mathrm{NaCl}$, $2.5 \mathrm{KCl}, 2 \mathrm{MgSO}_{4}, 1.25 \mathrm{NaH}_{2} \mathrm{PO}_{4}, 26 \mathrm{NaHCO}_{3}, 2 \mathrm{CaCl}_{2}$, and 10 $\mathrm{D}$-glucose and then maintained at room temperature. Individual slices were transferred to the recording chamber and continuously superfused with oxygenated ACSF at $32^{\circ} \mathrm{C}$. Somatic whole-cell voltage-clamp recordings were made in CA1 pyramidal cells with 4-7 M $\Omega$ glass electrodes filled with an internal solution containing the following (in $\mathrm{mM}$ ): 120 K-gluconate, $10 \mathrm{KCl}, 2$ EGTA, 10 HEPES, $4 \mathrm{Mg}$-ATP, $2 \mathrm{MgCl}_{2}$, and 10 $\mathrm{Na}_{2}$-phosphocreatine, $\mathrm{pH}$ adjusted to 7.4. The seal resistance of all recordings was 2-8 G $\Omega$. Recordings were acquired with Axopatch Multiclamp 700B amplifier, Digidata 1440A digitizer, and pClamp 10.3 software (Molecular Devices). The sampling rate was set at $10 \mathrm{kHz}$ in voltage-clamp mode and low-pass filtered at $2 \mathrm{kHz}$. Cells were held at $-70 \mathrm{mV}$ and spontaneous AMPAR miniature EPSCs (mEPSCs) were isolated by applying $20 \mu \mathrm{M} \mathrm{BIC}$ and $50 \mu \mathrm{M}$ AP5 to block GABA and NMDA receptor responses, respectively. After $5 \mathrm{~min}$ of baseline recording, CX614 was applied (20 $\mu \mathrm{M}$ for $5 \mathrm{~min}$ ). All AMPA mEPSCs were completely blocked by $10 \mu \mathrm{M}$ CNQX at the end of the experiments. CX614 stock solution was prepared daily in $2000 \times$ DMSO and diluted in ACSF. mEPSC peak amplitude and decay time $(\tau)$ were extracted with Clampfit 10.2. Baseline parameters were calculated from 300 to 2000 mEPSCs. Drug treatment parameters were calculated from 60 to 2000 mEPSCs. For each cell, amplitude and $\tau$ values during drug were normalized by the baseline mean.

Western blots. Five litters of rats were used to collect whole hippocampal protein samples at P17-P19 and P22-P24. Three to four animals were represented in each age group for each litter. Hippocampi were homogenized in ice-cold homogenization buffer ( $0.32 \mathrm{~m}$ sucrose, $4 \mathrm{~mm}$ HEPES, and protease inhibitors) and centrifuged at $1000 \times g\left(15 \mathrm{~min}, 4^{\circ} \mathrm{C}\right)$. Pellets were resuspended in homogenization buffer and centrifuged at $10,000 \times g$. This crude fraction was lysed before a final ultracentrifuge at $25,000 \times g$ for $20 \mathrm{~min}$ at $4^{\circ} \mathrm{C}$ for the isolation of the synaptosomal membrane fraction. Protein samples $(30 \mu \mathrm{g})$ and standard ladders were run through $7 \%$ SDS-polyacrylamide gels and transferred overnight to nitrocellulose membranes $(0.45 \mu \mathrm{m}) . \alpha$-GluR1 (1:100; Millipore), $\alpha$-GluR3 (1:50; Millipore), $\alpha$-Stargazin (1:50; Millipore), or $\alpha$-actin (1: 200; Millipore) primary antibodies were applied to separate nitrocellulose strips containing electrophoretically separated protein bands from both age groups and subsequently incubated in alkaline phosphataseconjugated secondary antibody (goat anti-rabbit or goat anti-mouse IgG; Millipore). Strips were washed in blocking solution and developed in NBT/BCIP. Band intensities were extracted using GeneTools software (GBox Chemi XT4; Syngene). GluA1, GluA3, and Stargazin (transmembrane AMPAR regulatory proteins [TARP]) band intensities were normalized by actin band intensities within each protein sample. Relative band sizes of interest were as follows: GluA1, $106 \mathrm{kDa}$; GluA3, $\sim 110$ $\mathrm{kDa}$, and Stargazin, $\sim 35 \mathrm{kDa}$ (according to the manufacturer and confirmed experimentally).

Statistical analyses: Two-way ANOVAs (age $\times$ drug) were used to compare across behavior groups followed by Tukey HSD and Bonferroni tests to identify individual group differences. Two-way repeatedmeasures ANOVAs were used to compare across electrophysiological I/O and ISI curves, followed by Tukey and Bonferroni tests. One-sample $t$ 
tests were used to determine age-related changes in protein levels (older/ younger protein ratios compared with 1) and to identify LTP induction (normalized EPSP slope values compared with 100\%). A one-way ANOVA was applied to evaluate group differences in LTP magnitude. Pearson correlation coefficients were calculated and two-way ANOVA interaction analyses were performed on the vicarious trial and error (VTE) alternation plots. All bar graphs show means with error bars that are SEM. All statistical analyses were performed with Excel (Microsoft) and SPSS software.

\section{Results}

Pharmacological prolongation of AMPAR responses enables mature maze navigation in juvenile rats

To determine whether excitatory synaptic function limited hippocampal engagement at the end of the third postnatal week, we delivered positive modulators of AMPARs (CX614 or CX929; Cortex Pharmaceuticals) by intraperitoneal injection to developing rats at P17-P19 or P22-P24 and measured spontaneous alternation rate in a Y-maze as an index of hippocampal integrity (Douglas et al., 1973). These drugs reduce AMPAR desensitization and deactivation, prolong glutamatergic synaptic responses, and are able to cross the blood-brain barrier (Arai and Kessler, 2007). Thirty minutes after injection, each animal was placed in the Y-maze for $8 \mathrm{~min}$. Analysis of the number of arm entries revealed a tendency for greater activity levels at P17-P19 than at P22-P24 (two-way ANOVA: CX614, $F_{(2,55)}=5.01, p<0.03$; CX929, NS). Neither AMPAR modulator affected the total number of arm entries. However, alternation rate was affected by age (two-way ANOVA: CX614, $F_{(1,55)}=19.51, p<0.0001$; CX929, $\left.F_{(1,47)}=19.51, p<0.001\right)$ and drug dose $\left(\mathrm{CX} 614: F_{(2,55)}=3.17\right.$, $p<0.05$, CX929: $\left.F_{(2,47)}=4.32, p<0.02\right)$ (Fig. $1 A, B$, left). Pairwise analyses revealed higher alternation rates in vehicletreated animals at P22-P24 compared with P17-P19 (Tukey HSD: CX614, $p<0.01$; CX929, $p<0.01)$. This age effect was robust to seasonal variation in litter size, which can alter developmental rate (observable as a consistent age difference in vehicle-treated controls despite variability across drug experiments). At P17-P19, but not P22-P24, the alternation rate was increased by low-dose CX614 or CX929 (versus vehicle, Tukey HSD, CX614, $p<0.01$; CX929, $p<0.01$ ) and high-dose CX614 treatment $(p<0.05)$. Although there was no correlation between the number of arm entries and the alternation rate (data not shown), a trend for an age effect on arm entries prompted analysis of alternation rate normalized for total number of arm entries (Fig. $1 A, B$, right, Alt/Arm Entries). A similar pattern of age and drug effects was observed for Alt/Arm Entries. A significant effect of age on Alt/Arm Entries was observed for CX614 $\left(F_{(1,61)}=\right.$ 7.767, $p<0.01$; Bonferroni for vehicle-treated controls, $p<$ $0.05)$, but not for $\operatorname{CX929}\left(F_{(1,52)}=1.365, p=0.12\right)$. Given that CX614 and CX929 produced significant increases in alternation rate, we applied a one-tailed test for the effect of drug on Alt/Arm Entries and found a significant main effect for CX614 (ANOVA, $\left.F_{(2,61)}=2.925, p<0.05\right)$. Like the alternation rate, Alt/Arm Entries was increased by CX614 at P17-P19 (Tukey HSD, 0 vs 2.5 $\mathrm{mg} / \mathrm{kg}, p<0.05)$, but not by CX929. These data show that behavioral indices of hippocampal maturity are elicited at P17-P19 by acute treatment with drugs that prolong glutamatergic synaptic responses, suggesting that glutamatergic synaptic excitation limits hippocampal function before the end of the third postnatal week.

To determine whether the alternation rate could be increased at P17-P19 by other factors that influence the excitation to inhibition balance, we delivered BIC, an antagonist, to GABA type-A receptors. BIC did not affect the total number of arm entries at
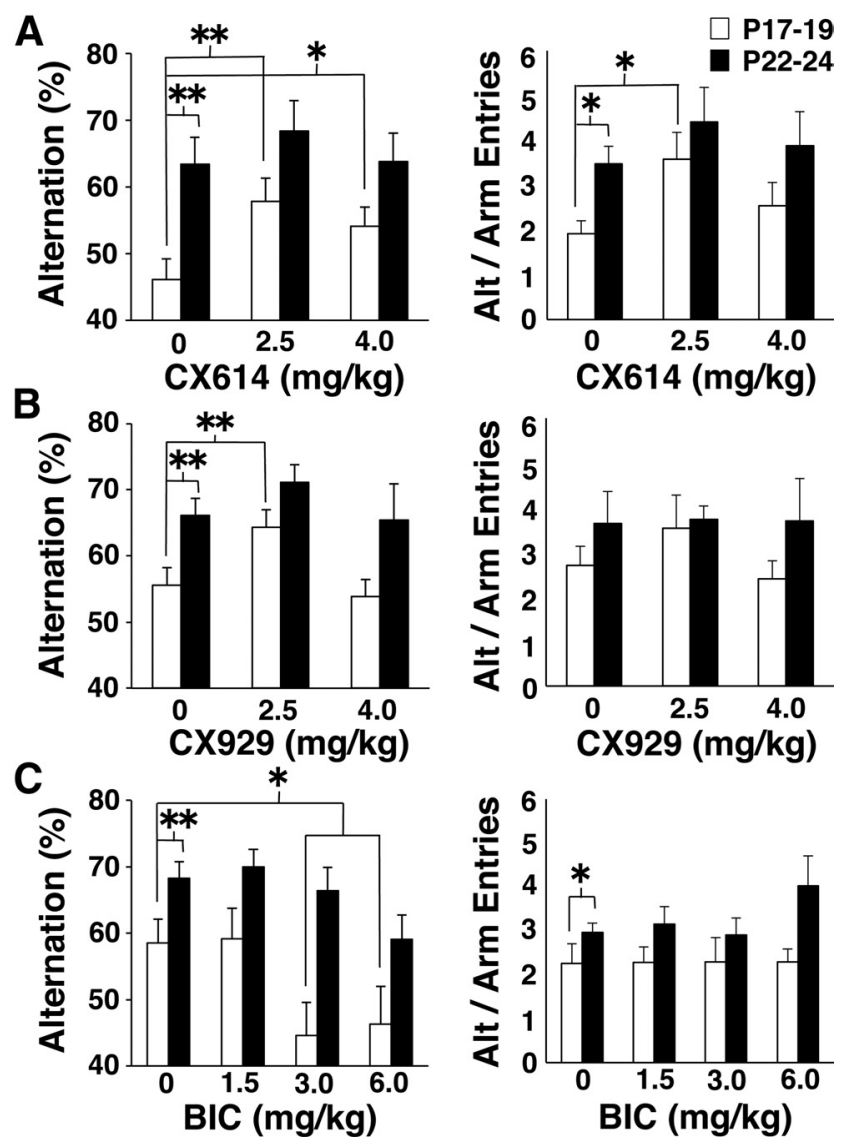

Figure 1. Spontaneous alternation measures in the Y-maze after delivery of drug or vehicle (cyclodextrin or PBS). Average percent alternation [Alternation (\%), left] and alternation rate divided by the number of arm entries (Alt/Arm Entries, right) are shown for each age and drug dose. $\boldsymbol{A}$, Alternation (\%) and Alt/Arm entries for animals receiving CX614. B, Alternation (\%) and Alt/Arm entries for animals receiving CX929. C, Alternation (\%) and Alt/Arm entries for animals receiving BIC. Asterisks denote significant group differences: ${ }^{*} p<0.05$; ${ }^{* *} p<0.01$. Number of subjects per group ranges from 6 to 13.

either age. There were main effects of age (two-way ANOVA: $\left.F_{(2,55)}=3.28, p<0.05\right)$ and $\operatorname{drug}\left(F_{(2,55)}=23.60, p<0.0001\right)$ on alternation rate and a main effect of age on Alt/Arm Entries $\left(F_{(1,65)}=8.97, p<0.005\right)$ (Fig. $\left.1 C\right)$. In vehicle-treated controls, the alternation rate (Bonferroni: $p<0.001$ ) and Alt/Arm Entries (Bonferroni: $p<0.05$ ) were higher at P22-P24 compared with $\mathrm{P} 17-\mathrm{P} 19$. Significant reductions in alternation rate were observed with higher doses of BIC at P17-P19 (Tukey HSD, relative to vehicle: $3 \mathrm{mg} / \mathrm{kg}: p<0.05,6 \mathrm{mg} / \mathrm{kg}: p<0.05)$ and at P22-P24 (relative to vehicle: $6 \mathrm{mg} / \mathrm{kg}: p<0.05$ ). BIC did not increase the alternation rate or Alt/Arm Entries at any of the tested doses. Therefore, the increased alternation rate produced by CX614 and CX929 at P17-P19 was not caused by a general shift in the excitation to inhibition balance, but was specific to modulation of AMPAR-mediated synaptic responses.

VTE is a label for the behavior of actively scanning choices before making a selection (Muenzinger, 1938; Tolman, 1938). VTE in rats is associated with deliberative spatial processing and requires the hippocampus ( $\mathrm{Hu}$ and Amsel, 1995; Papale et al., 2012). To assess the involvement of a deliberative spatial strategy in spontaneous alternation, we measured VTE for subjects $(n=45)$ that had video detail to resolve head and upper body motions (micromovements [MMs]) toward each arm when the animal paused before performing an arm choice. Although the alternation rate was higher at P22-P24 compared with 


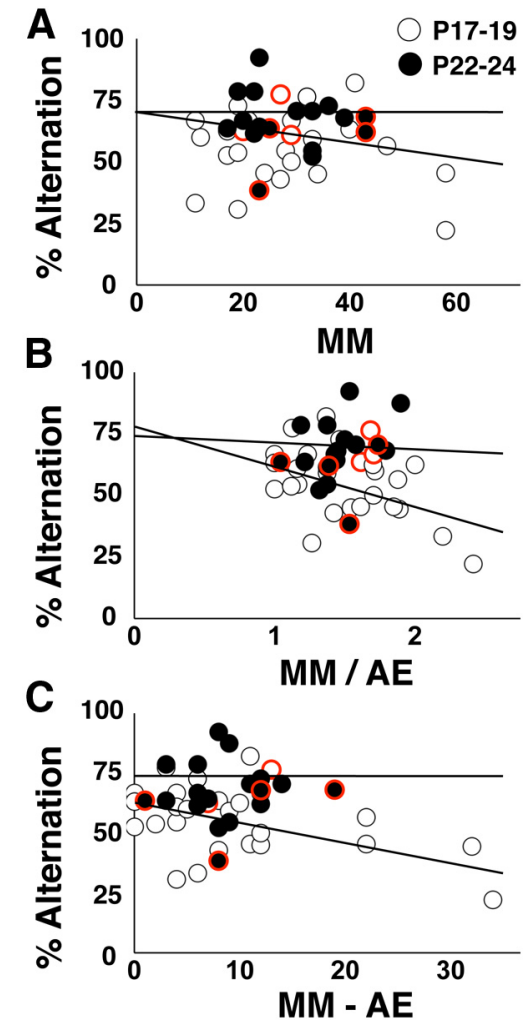

Figure 2. Assessment of VTE in the Y-maze. This dataset consists of a subset of animals pseudorandomly selected from all Y-maze experiments in Figure 1 supplemented with additional vehicle-treated animals at both testing ages. $\boldsymbol{A}$, Spontaneous alternation rate plotted against MMs. $\boldsymbol{B}$, Spontaneous alternation rate plotted against MM divided by number of arm entries (MM/AE). Alternation rate was negatively related to MM/AE at P17-P19 $(p<0.03)$, but not P22-P24, and the regression lines differ across testing ages $(p<0.03)$. C, Spontaneous alternation rate plotted against $M M$ minus the number of arm entries (MM $-A E$ ). Alternation rate was negatively related to MM - AE at P17-P19 $(p<0.05)$, but not P22-P24, and the regression lines differ across testing ages $(p<0.05)$. There are 27 data points at P17-P19 and 18 data points at P22-P24. Data points with red borders indicate XX614 treatment. Note that nearly all of these data points reside near the top of the alternation scale.

P17-P19 (P17-P19: $55.1+3.8$; P22-P24: $66.9+3.9 ; t_{(44)}=$ 2.63, $p<0.02)$, there were no age differences in the total number of MMs (P17-P19: $27.3+3.5$; P22-P24: $27.9+2.7)$, arm entries (P17-P19: 18.1 + 2.0; P22-P24: $19.4+1.8$ ), MMs/arm entries (P17-P19: 1.56 + 0.10; P22-P24: $1.45+$ 0.07), or MMs - arm entries per session (P17-P19: 10.3 + 2.3; P22-P24: $8.6+1.4)$. We found a significant negative correlation between alternation rate and normalized VTE scores for animals at P17-P19 (MMs/arm entries, $R^{2}=0.19, p<0.03$, $n=27$; MMs - arm entries, $\left.R^{2}=0.17, p<0.05, n=27\right)$, but not P22-P24 (Fig. $2 B, C$ ). In addition, the regression lines for MMs/arm entries and MMs - arm entries were statistically different across age groups (two-way ANOVA interaction analysis: MMs/arm entries: $t_{(25)}=-2.439, p<0.03$; MMs arm entries: $\left.t_{(25)}=-2.222, p<0.05\right)$, indicating a stronger relationship between alternation rate and VTE in animals $<3$ weeks of age. Greater deliberation may be expressed as a compensatory response to poor spatial memory at this age.

To verify that the age or drug effects on alternation in the Y-maze were not due to changes in risk assessment or anxiety levels, we exposed developing rats to an EPM 30 min after delivery of CX614 or vehicle and measured the number of crossings into open arms and open arm dwell time as indices of anxiety level (Walf and Frye, 2007). There was no main effect of age or


Figure 3. Effects of age and (X614 on EPM behavior parameters. $A$, Averaged number of entries into open arms (including the center square) for all age and drug combinations. $\boldsymbol{B}$, Averaged time spent in open arms (including the center square) for all age and drug combinations. There were no effects of age or drug on open arm entries or open arm dwell time. Number of subjects per group ranges from 9 to 15 .

drug on the number of crossings into open arms (Fig. 3A) or time spent exploring the open arms (Fig. 3B). Therefore, the developmental and drug-induced increases in alternation rate in the Y-maze are not a result of changes in fear or anxiety, but rather are likely due to enhanced spatial processing.

\section{Synaptically driven postsynaptic excitability increases with} increasing age at the end of the third postnatal week

To explore relationships between the maturation of spatial navigation and excitatory synaptic transmission, we prepared hippocampal slices from animals at P17-P19 and P22-P24 and recorded electrically evoked field responses in the stratum radiatum of area CA1. Analysis of I/O curves revealed no age effects on the FP amplitude (Fig. 4A) or EPSP slope (Fig. 4B). To test for developmental alterations in presynaptic short-term plasticity, we set the stimulation intensity to evoke conditioning EPSPs of 1 $\mathrm{mV}$ in amplitude, applied pairs of stimulus pulses with varying ISIs, and analyzed PPF. There were no main effects of age or ISI. Although there was a separation between age groups in mean PPF at the $25 \mathrm{~ms}$ ISI, there was no interaction between age and ISI (two-way repeated-measures ANOVA: $F_{(3,43)}=0.713, p=0.403$; Fig. $4 C$ ). These data suggest that alterations in baseline excitatory synaptic efficacy and short-term synaptic plasticity are not directly involved in the late postnatal behavioral maturation.

Simultaneous recording at the cell body layer allowed for evaluation of developmental differences in postsynaptic excitation. Analysis of the PS to EPSP ratio revealed developmental alterations in synaptically driven postsynaptic excitation (two-way repeated-measures ANOVA, age by stimulation intensity interaction: $F_{(4,43)}=5.808, p<0.002$; Fig. $5 A$ ). The PS to EPSP ratio was increased at P22-P24 compared with P17-P19 when stimulation intensity was low (Bonferonni: age difference at $100 \mu \mathrm{A}$, 




B
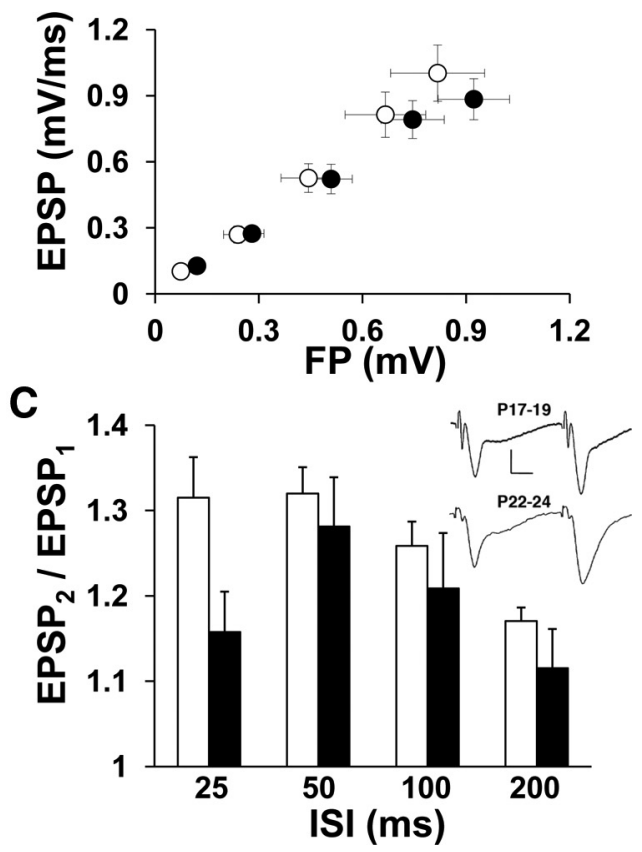

Figure 4. Baseline I/0 and ISI curves for electrically evoked field responses recorded from stratum radiatum of area $\mathrm{CA} 1$ in hippocampal slices. $A$, Average $\mathrm{FP}$ amplitude is plotted against stimulation intensity for both age groups. The FP amplitude increased with increasing stimulation intensity (two-way repeated-measures ANOVA: $p<0.0001$ ). $\boldsymbol{B}$, Average EPSP slope is plotted against mean FP amplitude for both age groups. EPSP slope increased across FP levels (two-way repeated-measures ANOVA: $p<0.0001)$. C, The ratio of the test EPSP slope to the conditioning EPSP slope (PPF) is plotted against ISI for both age groups. PPF was altered as a function of ISI (two-way repeated-measures ANOVA: $p<0.0001$ ), but not age. Inset shows averaged traces (10 sweeps each) from one experiment at $50 \mathrm{~ms} I S I$ for each age group. Scale bars, $10 \mathrm{~ms}$ and $0.5 \mathrm{mV}$. Number of slices per group ranges from 19 to 25 .

$p<0.02$ ), but increased at P17-P19 compared with P22-P24 when stimulation intensity was high (Bonferonni: age difference at $400 \mu \mathrm{A}: p<0.05)$. Because responses to lower stimulation intensities are more reflective of normal physiological conditions, it appears that the ability of excitatory synapses to drive postsynaptic discharge increases at the end of the third postnatal week. Because we did not observe age differences in basic parameters of excitatory synaptic transmission that would drive the developmental increase in postsynaptic excitability, we evaluated PPI (the ratio of the second PS to the first PS amplitude) as a measure of GABAergic synaptic inhibition (Rogers and Hunter, 1992). The ratio of the second to the first PS amplitude was consistently smaller at P22-P24 than at P17-P19 (two-way repeated-measures ANOVA: $\left.F_{(1,38)}=17.49, p<0.0001\right)$, indicating greater PPI and suggesting more fully developed GABAergic inhibition at P22-P24 (Fig. 5B). Therefore, the reduction in
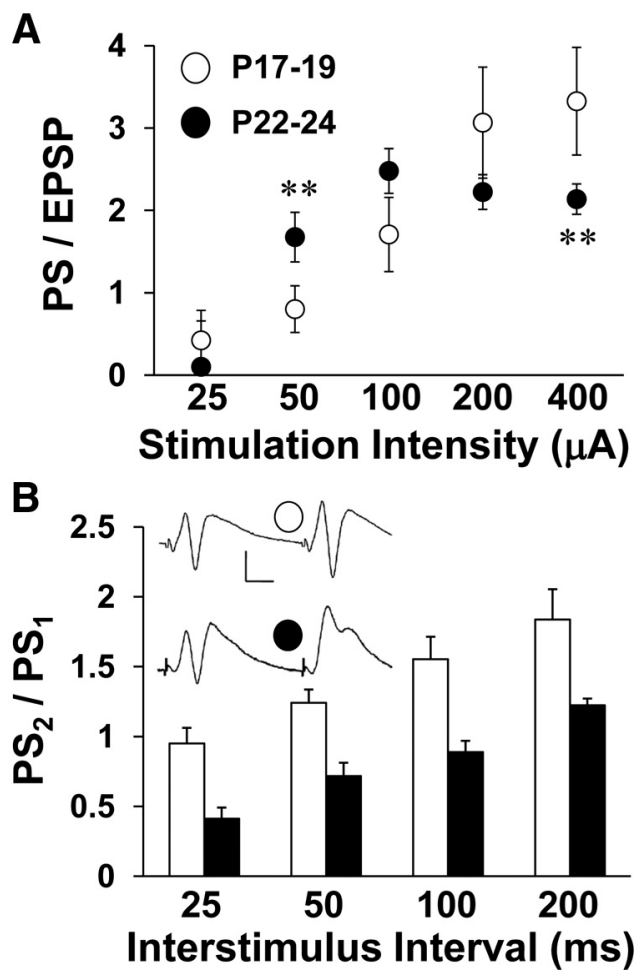

Figure 5. Baseline I/O and ISI curves for electrically evoked field responses recorded in stratum pyramidale of hippocampal slices. Stimulation intensity and paired-pulse ISIs were varied. $A$, Average PS to EPSP ratio is plotted against stimulation intensity for both age groups. Asterisks represent significant group differences: ${ }^{* *} p<0.01$. $\boldsymbol{B}$, Ratio of the test PS amplitude to the conditioning PS amplitude is plotted against ISI for both age groups. Inset shows averaged traces (10 sweeps each) from one experiment at $50 \mathrm{~ms}$ ISI for each age group. Scale bars, $10 \mathrm{~ms}$ and $0.5 \mathrm{mV}$. Number of slices per group ranges from 20 to 25 .

postsynaptic excitability observed at P17-P19 at lower stimulation intensity is likely not a result of enhanced GABAergic transmission, as one would predict the opposite age effect on PPI. Instead, the developmental increase in postsynaptic excitability is more directly related to stronger coupling between excitatory synaptic transmission and postsynaptic discharge.

\section{Pharmacological prolongation of AMPAR responses in} juveniles enhances postsynaptic excitability more at P17-P19 than at P22-P24

To test the notion that postsynaptic excitability could be differentially regulated by excitatory synapses at the end of the third postnatal week, we recorded evoked EPSPs and PSs in area CA1 during a 15 min application of CX614 at P17-P19 and P22-P24. CX614 did not affect the EPSP slope (Fig. 6A,B), but increased the PS at both testing ages (Fig. 6C,D). The drug-induced increase in the PS was greater at P17-P19 compared with P22-P24 at 20 $\mu \mathrm{M}$ (unpaired $t$ test: $t_{(29)}=3.00, p<0.006$ ), but not at $40 \mu \mathrm{M}$. These data agree with the behavioral results showing the greatest age difference in the effects of moderate doses of CX614 and CX929 on alternation rate and further substantiate the hypothesis that reduced EPSP duration at SC-CA1 synapses limits postsynaptic excitation in area CA1 and restricts hippocampal contribution to behavior in juvenile animals.

Evoked AMPAR EPSPs and spontaneous AMPAR mEPSCs decay more slowly at P22-P24 than at P17-P19

The initial EPSP slope, which is typically used to measure synaptic strength, may not capture other meaningful changes in the 
A



B
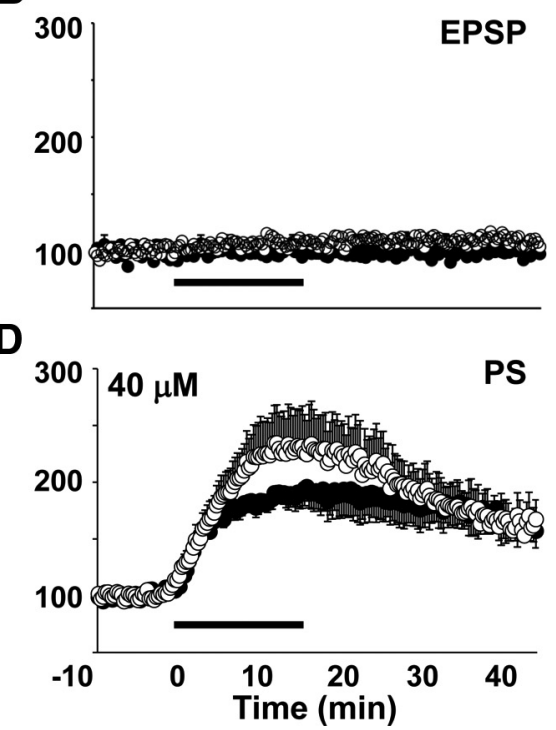

Figure 6. Effects of $X X 614$ on EPSP slope and PS amplitude at P17-P19 and P22-P24. Stimulating and recording electrodes were placed the same as for I/0 and ISI experiments. Timelines display normalized EPSP slope $(\boldsymbol{A}, \boldsymbol{B})$ and PS values $(\boldsymbol{C}, \boldsymbol{D})$ during baseline, drug exposure, and washout. Drug delivery is indicated by a solid bar below the timelines $(A, C, 20 \mu \mathrm{m} ; \boldsymbol{B}, \boldsymbol{D}, 40 \mu \mathrm{m})$. Inset in $\boldsymbol{A}$ shows overlaid averaged traces (10 sweeps each) taken during baseline and $20 \mu \mathrm{m}$ drug exposure. Scale bars, $1 \mathrm{mV}, 10 \mathrm{~ms}$. Asterisks represent significant group differences: ${ }^{* *} p<0.01$. Number of slices per group ranges from 9 to 20 .

dynamics of synaptic excitation. Because CX614 increases the duration of hippocampal glutamatergic EPSPs (Arai et al., 2000) and increases spontaneous alternation rate at $\mathrm{P} 17-\mathrm{P} 19$, it is possible that the age-related increase in alternation rate might also result from increased duration of synaptic responses. We investigated the possibility that AMPAR response duration is altered at the end of the third postnatal week by recording pharmacologically isolated AMPAR responses in hippocampal slices prepared from animals at both testing ages. We applied AP5 $(10 \mu \mathrm{M})$ to block NMDARs and BIC $(2 \mu \mathrm{M})$ to block GABA type-A receptors and adjusted the stimulation intensity to evoke AMPAR responses at amplitudes of $0.5,1.0$, and $1.5 \mathrm{mV}$. AMPAR response half-width and $\tau$ were increased at P22-P24 compared with P17-P19 (two-way repeated-measures ANOVA: half-width: $F_{(1,38)}=15.173, p<0.001$; $\tau: F_{(1,51)}=5.41, p<0.05$; Fig. $\left.7 A, B\right)$. Half-width and $\tau$ decreased with increasing EPSP amplitude (half-width: $F_{(2,37)}=72.640, p<$ $\left.0.0001 ; \tau: F_{(2,86)}=149.490, p<0.001\right)$ due to the reflection of the PS in the synaptic field recording. However, this does not explain the age difference in the AMPAR response dynamics. Previous work showed that pharmacological blockade of AMPAR deactivation, but not desensitization, resulted in longer duration synaptic responses (Arai et al., 2000). Therefore, the current finding of prolonged AMPAR responses suggests a developmental reduction in AMPAR deactivation. Moreover, prolonged AMPAR responses would explain the enhanced postsynaptic excitability with increasing age and possibly the increase in spontaneous alternation rate at P22-P24.

Because the later phases of evoked excitatory synaptic potentials in extracellular field recordings are subject to contamination by other physiological events (disynaptic transmission, postsynaptic discharge), we performed whole-cell intracellular recording from CA1 pyramidal neurons in slices collected at P17-P19 and P22-P24. In voltage-clamp mode, without stimulation, spontaneous mEPSCs could be observed ( $-70 \mathrm{mV}$ holding potential). As performed for the field recordings, we pharmacologically isolated AMPAR mEPSCs with AP5 $(50 \mu \mathrm{M})$ and BIC $(20 \mu \mathrm{M})$ and then applied CX614 (20 $\mu \mathrm{M}, 5 \mathrm{~min})$. There were no differences in mean mEPSC amplitude (pA) or frequency (mEPSCs/s) across age groups. There were significant effects of age (two-way repeated-measures ANOVA: $\left.F_{(1,24)}=4.402, p<0.05\right)$ and drug $\left(F_{(1,24)}=13.579, p<0.005\right)$ on the $\tau$ of recorded mEPSCs. The baseline AMPAR mEPSC $\tau$ was increased at P22-P24 compared with P17-P19 (Bonferroni: $p<$ 0.05; Fig. 8). mEPSC $\tau$ was increased by CX614 at P17-P19 (Bonferroni: $p<$ 0.002 ) and at P22-P24 (Bonferroni: $p<$ 0.002 ), but there was no age difference in normalized $\tau$ values (unpaired $t$ test). These results are in close agreement with findings from extracellular recordings and confirm an increase in AMPAR response duration with increasing age at the end of the third postnatal week.

Threshold for induction of activitydependent synaptic potentiation is reduced by CX614 at P17-P19

We previously showed that the activation threshold for induction of LTP at SC-CA1 synapses decreased at the end of the third postnatal week (Dumas, 2012), supporting the hypothesis that circuit deficits before the end of the third postnatal week included insufficient sensitivity to plasticity induction in area CA1. In addition, it has been shown that positive allosteric modulators of AMPARs facilitate LTP induction in the hippocampus (Arai and Kessler, 2007). Therefore, it is possible that CX614 increased alternation rates at P17-P19 by reducing the threshold for LTP induction. To test this, we applied a perithreshold stimulation frequency ( 100 pulses at $20 \mathrm{~Hz}$ derived from Dumas, 2012) in the absence or presence of a low concentration of CX614 (5 $\mu \mathrm{M}, 15 \mathrm{~min}$ terminating at induction) in slices prepared at P17-P19. In the absence of LTP-inducing stimulation, CX614 did not affect the EPSP slope and, without CX614 present, LTP was not induced by perithreshold stimulation (Fig. 9). In contrast, with CX614 present, perithreshold stimulation induced LTP (one-way ANOVA, $F_{(3,44)}=6.70, p<0.001 ; 20$ $\mathrm{Hz} / 5 \mu \mathrm{M}$ vs $20 \mathrm{~Hz} / 0 \mu \mathrm{M}: p<0.05)$. In addition, LTP was induced in slices prepared at P22-P24 in the absence of CX614. These data indicate that CX614 overcame the developmental impedance to LTP induction in slices prepared from at P17-P19, giving credence to the notion that the CX614-dependent increase in alternation rate at $\mathrm{P} 17-\mathrm{P} 19$ resulted from facilitation of the induction of activity-dependent synaptic potentiation.

GluA1 subunit expression is reduced, whereas GluA3 subunit and TARP expression levels are increased, at the end of the third postnatal week

To investigate the molecular basis for the differential effects of AMPAR modulators on spatial behavior and hippocampal synaptic physiology, we performed Western blot assays on hippocampal protein extracts for AMPAR subunits and TARPs known to alter AMPAR desensitization and deactivation (Tomita et al., 2003; Suzuki et al., 2008). Example bands for each antibody at each age group are shown in Figure 10A. To compare across ages, we divided normalized band intensities at P22-P24 by P17P19 to obtain an Older to Younger ratio (Fig. 10B). The Older/ Younger value for GluA1 was significantly lower than 1, 

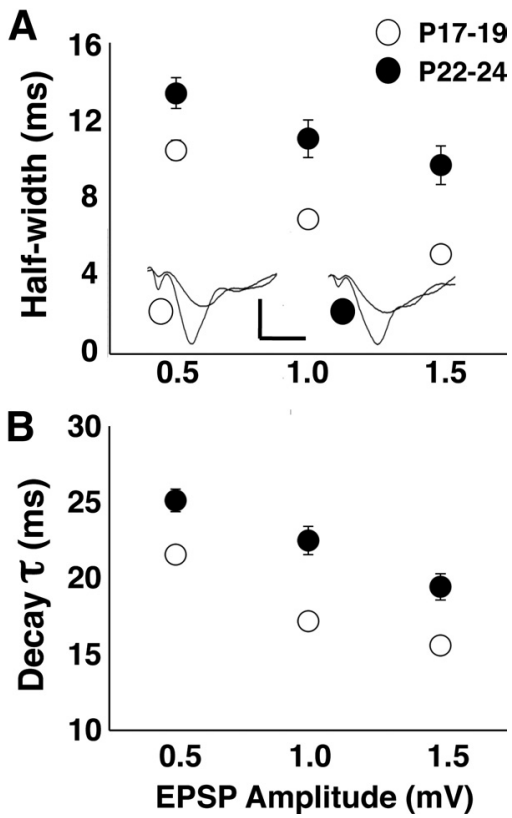

Figure 7. Population extracellular AMPAR EPSPs are prolonged with increasing age at the end of the third postnatal week. A, AMPAR EPSP half-width is greater at P22-P24 than at P17-P19. Inset shows averaged (10 sweeps each) overlaid waveforms of EPSPs evoked at 0.5 and $1.0 \mathrm{mV}$. Scale bars, $0.5 \mathrm{mV}, 10 \mathrm{~ms}$. B, AMPAR EPSP $\tau$ is greater at P22-P24 than at P17-P19. Number of slices per group ranges from 22 to 25 .

indicating a reduction in GluA1 expression with increasing age (one-sample $t$ test: $p<0.02$ ). Conversely, the Older/Younger values for GluA3 and TARP were significantly $>1$, indicating an increase in GluA3 and TARP expression with increasing age (GluA3, $p<0.01$; TARP, $p<0.05$ ). These data support the hypothesis that more hippocampal AMPARs containing GluA3 subunits become associated with TARP at P22-P24, which would explain the differential drug effects and the increase in baseline AMPAR half-width in animals older and younger than 3 weeks of age.

\section{Discussion}

We replicated previous work (Douglas et al., 1973; Dumas, 2004) by showing a significant increase in spontaneous alternation rate at the end of the third postnatal week and extended this finding by showing that the increase in alternation rate with increasing age remained after normalizing for the number of arm entries. We further demonstrated an inverse relationship between alternation rate and VTE at P17-P19, but not P22-P24, suggesting that hippocampal-dependent processes are involved in the final maturation of spatial alternation. The developmental deficit in alternation rate was eliminated by drugs that prolong glutamatergic synaptic responses in the hippocampus in vitro and in vivo (Arai and Kessler, 2007), but not after blockade of GABAergic inhibition, implicating alterations in excitatory synapses in the developmental increase in alternation rate. In hippocampal slices, AMPAR response duration and

A

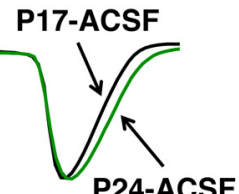

P24-ACSF
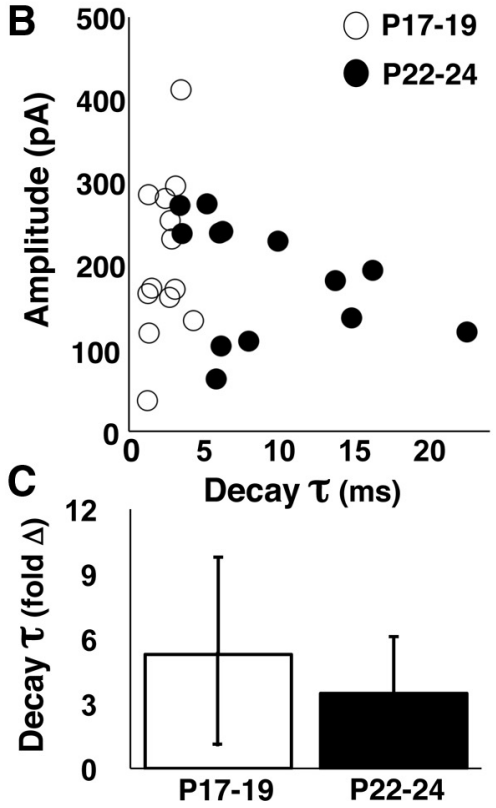

Figure 8. Whole-cell intracellular AMPAR mEPSCs are prolonged with increasing age at the end of the third postnatal week. $\boldsymbol{A}$, Averaged scaled mEPSC waveforms (100 mEPSC traces per waveform) compared across age groups (left) and compared across baseline and drug exposure for each age group (middle, right). $\boldsymbol{B}$, Averaged baseline mEPSC peak amplitude plotted against average $\tau$ for each cell. Bar graphs at right show group means for peak amplitude (Amp), mEPSC frequency (Freq, mEPSCs/s), and $\tau$ during baseline. Only $\tau$ differs across age groups (Bonferroni: $p<0.05$ ). $C$, Averaged normalized (change from baseline, fold change) $\mathrm{mEPSC} \tau$ during $20 \mu \mathrm{m}$ CX614 exposure at P17-P19 and P22-P24. Number of cells is 13 per age group.

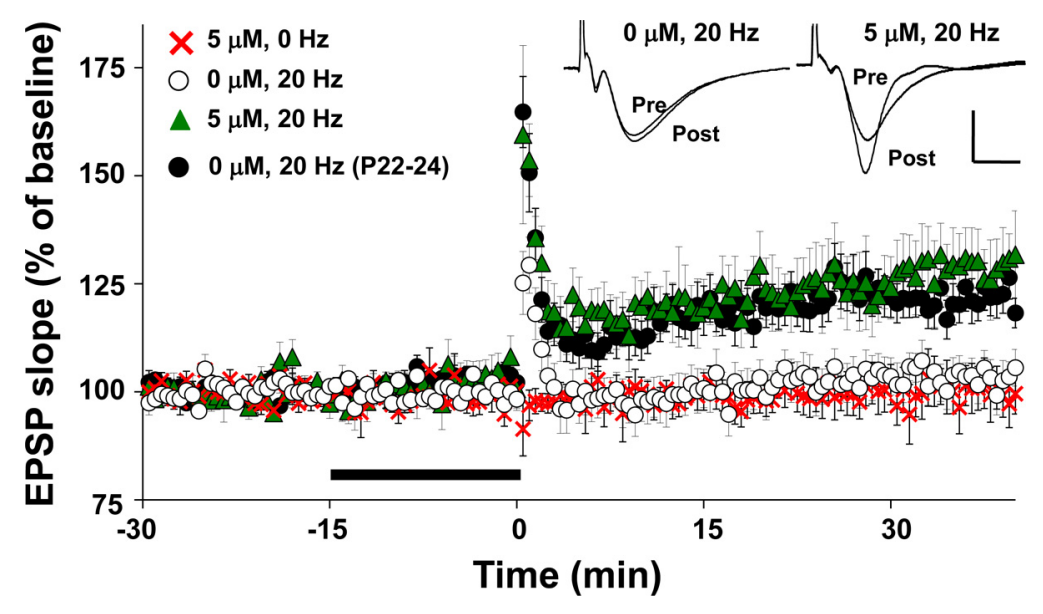

Figure 9. Averaged normalized timelines for LTP experiments in the presence and absence of $5 \mu \mathrm{m}$ CX614. All slices were prepared at P17-P19 except where noted. Stimulating and recording electrodes were placed the same as for baseline transmission experiments and baseline responses were set to elicit a $1 \mathrm{mV} \mathrm{PS.} \mathrm{A} 20 \mathrm{~Hz}$ burst (100 pulses) was applied at time 0 . Thick bar denotes CX614 delivery. Inset shows overlaid averaged traces (10 sweeps each) during baseline and at 36-40 min after induction for experiments on slices prepared at P17-P19. Scale bars, $1 \mathrm{mV}, 10 \mathrm{~ms}$. Number of slices per group ranges from 8 to 16 . 



Figure 10. Western blot images and group averages. Protein was extracted from whole hippocampal homogenates at P17-P19 and P22-P24 and probed with $\alpha$-GluA1, $\alpha$-GluA3, $\alpha$-Stargazin, or $\alpha$-actin primary antibody. A, Photos of GluA1, GluA3, and TARP bands with actin controls in blots containing protein samples collected at P17-P19 and P22-P24. B, Older/Younger ratio means for normalized band intensities. Asterisks represent significant group differences: ${ }^{*} p<0.05,{ }^{* *} p<0.02,{ }^{* * *} p<0.01$.
EPSP to PS coupling in area CA1 increased from P17-P19 to P22-P24. CX614 increased EPSP to PS coupling more at P17P19 compared with P22-P24 and reduced the threshold for LTP induction in slices prepared at P17-P19. Figure 11 illustrates how an increase in the association of GluA3-containing AMPARs with TARP $\gamma 8$ produces synaptic responses that are prolonged, which in turn enhances postsynaptic excitation and facilitates induction of activity-dependent synaptic potentiation, leading to spontaneous alternation rates that exceed chance levels. These findings suggest that increases in alternation rates resulting from treatment with positive allosteric modulators of AMPARs or increasing postnatal age share underlying biophysical mechanisms.

Our work clarifies some basic issues about hippocampal maturation. First, the $30 \mathrm{~min}$ drug incubation before maze exposure is likely insufficiently long to permit remodeling of gross neuronal architecture. Consistent with prior anatomical findings (Zimmer and Haug, 1978; Bayer, 1980a,b; Amaral and Dent, 1981), our results show that the hippocampus is structurally intact and appropriately interconnected before the end of the third postnatal week. Second, these drugs act predominantly on AMPARs on pyramidal cells as opposed to GABAergic interneurons (Xia and Arai, 2005). Therefore, it is likely that positive AMPAR modulators overcome deficits in spontaneous alternation at P17P19 by enhancing synaptic depolarization at glutamatergic synapses onto other excitatory neurons. Last, antagonism of inhibitory synaptic transmission with BIC did not replicate the effects of CX614 or CX929 on spontaneous alternation in immature animals, indicating that maturation of spontaneous alternation is not a result of a general shift in the excitation to inhibition balance.

Systemic drug delivery precludes direct assignment of behavioral modifications to specific brain structures. This is important because spontaneous alternation involves the hippocampus (Douglas, 1972) as well as the prefrontal cortex (Wall and Messier, 2000), which also exhibits late postnatal maturation (Watson and Stanton, 2009). However, AMPAKINEs have been shown to have greater effects in the hippocampus than other brain structures (Xia et al., 2005) and CX614 and CX929 increased the alternation rate in the Y-maze without affecting the total number of arm entries or behavior on the EPM. Open arm entries and time spent in open arms on the EPM are reduced by delivery of muscimol directly to the prefrontal cortex (Shah et al., 2004) and exposure to the EPM increases activity-dependent immediate early gene expression in ventral PFC structures, but not in the hippocampus (Albrechet-Souza et al., 2008). Therefore, one might expect any functional maturation of the prefrontal cortex from P17 to P24 to be reflected in our EPM data, which showed no age differences. These prior reports and our control experiment support the hippocampus as the primary brain structure responsible for the maturation of spontaneous alternation at 3 weeks of age. It will be interesting to also test the ability of juvenile rats to perform

Figure 11. Model illustrating the relationships among AMPAR composition, AMPAR response duration, postsynaptic excitability, plasticity induction threshold, and spatial behavior across age groups and with CX614. CX614 has a lower EC ${ }_{50}$ for AMPARs containing GluA1 (Arai et al., 2000), the predominant subunit expressed at P17-P19, and produces pronounced effects on postsynaptic excitability and synaptic plasticity, which may act together or separately to affect spontaneous alternation. Compared with P17-P19, application of (X614 or increasing age (P22-P24) produce very similar changes in electrophysiological parameters and spatial navigation.

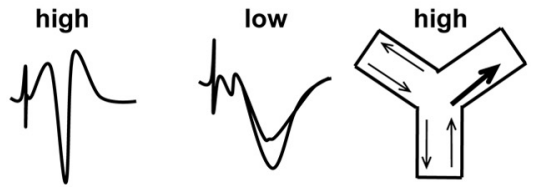

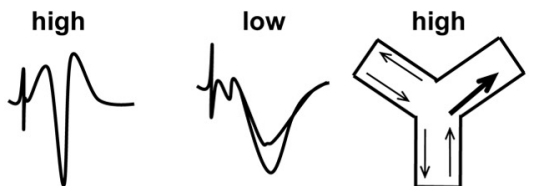


an attentional set-shift learning task that is nonspatial and has been shown to require the prefrontal cortex (Birrell and Brown, 2000).

The AMPAR protein complex, which includes AMPAR subunits and the TARP $\gamma 8$ isoform (Tomita et al., 2003; Jackson and Nicoll, 2011), is modified during hippocampal synapse development. AMPAR subunits (GluA1-GluA4) display increasing expression levels during the first two postnatal weeks (Durand and Zukin, 1993; Martin et al., 1998; Ritter et al., 2002). We extend these findings by showing a simultaneous decrease in GluA1 and increase in GluA3 from P17-P19 to P22-P24. In separate reports, high levels of TARP $\gamma 8$ expression were observed at P17 and P21 (Tomita et al., 2003; Fukaya et al., 2005). We found that TARP expression increased from P17-P19 to P22-P24. When coexpressed with TARP $\gamma 8$, both deactivation and desensitization were reduced in AMPARs containing GluA3 compared with GluA1 (Suzuki et al., 2008; Montgomery et al., 2009). Moreover, CX614 has lower $\mathrm{EC}_{50}$ values for $\left[{ }^{3} \mathrm{H}\right]$-AMPA binding to and inhibition of deactivation of AMPARs containing GluA1 compared with GluA3 (Arai et al., 2000). Therefore, a shift from GluA1 to GluA3 subunit incorporation and increased association of GluA3-containing AMPARs with TARP at P22-P24 likely explain the reduced impact of the AMPAR modulators on alternation behavior and synaptic physiology at P22-P24 and underlie the developmental increases in AMPAR response half-width and $\tau$.

Electrophysiological recordings in vitro and in vivo show that glutamatergic excitatory synaptic transmission develops later in area CA1 (Dumas and Foster, 1995; Durand et al., 1996; Wang et al., 2002) than in area CA3 (Bliss et al., 1974; Hussain and Carpenter, 2001) or the dentate gyrus (Bekenstein and Lothman, 1991). In addition, when developing rats are exposed to a Y-maze, expression of the immediate early gene fos is more robust in the dentate gyrus and area CA3 than in area CA1 at earlier ages (Waters et al., 1997). Because fos expression is activity dependent (Tischmeyer et al., 1990; Sagar and Sharp, 1993), reduced fos expression in area CA1 of developing animals supports a selective deficit in SC-CA1 synaptic function. Combined with the current findings, this suggests that the developmental increase in AMPAR response duration at SC-CA1 synapses acts to enhance spatial navigation by enhancing synaptic activation of CA1 pyramidal cells.

Stable place cells have been recorded in rats at $16 \mathrm{~d}$ of age (Langston et al., 2010; Wills et al., 2010) and place cell stability in adults is dependent on NMDAR activation (Kentros et al., 1998). Using place cell stability as a metric, it appears that NMDAR-dependent synaptic plasticity is driven by experience in juveniles. Because competent performance in spatial navigation tasks is not present until after three postnatal weeks, it seems that place cell encoding of context and NMDAR-dependent synaptic plasticity are not sufficient to support spatial navigation. Competing explanations are that place cell encoding in juvenile animals does not depend on NMDAR activation or that different forms of NMDARdependent synaptic plasticity support place cell stability and spatial navigation. Forms of activity-dependent synaptic potentiation that do not rely on NMDARs are more easily induced (Chavez-Noriega and Stevens, 1992; Velisek et al., 1993; Lauri et al., 2007, Dumas, 2012) and silent synapses are present in larger numbers in juveniles (Durand et al., 1996; BenAri et al., 1997; Liao et al., 1999). Theoretically, CX614 could induce silent synapses at P17-P19 to show AMPAR responses by increasing the sensitivity of synaptic AMPARs to low rates of glutamate release (Choi et al., 2000; Renger et al., 2001). However, we found no impact of CX614 on EPSP slope and previous work showed no alteration in the number of asynchronous synaptic responses recorded from neuronal cultures in the presence and absence of CX614 (Arai et al., 2000), which would be expected with silent synapse induction. Place cells (and even higher-order cell assemblies) that arise in area CA1 as a juvenile animal explores a maze may be a reflection of upstream hippocampal or cortical processing (Hayman and Jeffery, 2008) and may not require any plasticity per se on the part of hippocampal synapses. Therefore, the most parsimonious conclusion is that developmental plasticity mechanisms, regardless of whether they rely on NMDARs or reside in the hippocampus, appear sufficient to support place cell stability but cannot properly bind these cells into functional networks that represent space or support the act of navigating in relation to spatial cues.

Some rodent studies have suggested that the hippocampus matures only after the end of the fourth postnatal week, but these studies involved stunted growth (Bronstein and Spear, 1972), testing apparatuses that biased the animals toward the use of nonhippocampal learning strategies (Schenk, 1985), or habituation in the same environment before testing (Ainge and Langston, 2012). A larger dataset suggests intact spatial navigation just after the end of three postnatal weeks (for review, see Dumas, 2005a). Most assuredly, the hippocampus continues to develop and place cell responses continue to be refined beyond 3 weeks of age (Langston et al., 2010; Scott et al., 2011), which might underlie continued improvement of hippocampal-dependent spatial navigation and memory abilities. Prolonged AMPAR responses may reflect a necessary biological prelude or serve as a preliminary mechanistic explanation for such physiological refinement and cognitive improvement. The current work highlights basic aspects of synaptic physiology that appear to be part of the core processes necessary for spatial navigation, including prolonged AMPAR responses, efficient coupling between excitatory synaptic depolarization and postsynaptic discharge, and an appropriate threshold for the induction of NMDAR-dependent synaptic potentiation. Our results contribute to the notion that the hippocampus develops in a stepwise fashion both on the behavioral and neural levels, with physiological components of cognitive maps emerging before the ability to use stored maps to navigate, followed by long-lasting memories for spatial routes and goals.

\section{References}

Ainge JA, Langston RF (2012) Ontogeny of neural circuits underlying spatial memory in the rat. Front Neural Circuits 6:1-10. CrossRef Medline

Albrechet-Souza L, Borelli KG, Brandão ML (2008) Activity of the medial prefrontal cortex and amygdala underlies one-trial tolerance of rats in the elevated plus-maze. J Neurosci Methods 169:109-118. CrossRef Medline

Amaral DG, Dent JA (1981) Development of the mossy fibers of the dentate gyrus: I. A light and electron microscopic study of the mossy fibers and their expansions. J Comp Neurol 195:51-86. Medline

Arai AC, Kessler M (2007) Pharmacology of ampakine modulators: from AMPA receptors to synapses and behavior. Curr Drug Targets 8:583-602. CrossRef Medline

Arai AC, Kessler M, Rogers G, Lynch G (2000) Effects of the potent ampakine CX614 on hippocampal and recombinant AMPA receptors: interactions with cyclothiazide and GYKI 52466. Mol Pharmacol 58:802-813. Medline

Bayer SA (1980a) Development of the hippocampal region in the rat I: neurogenesis examined with $3 \mathrm{H}$-thymidine autoradiography. J Comp Neurol 190:87-114. CrossRef Medline

Bayer SA (1980b) Development of the hippocampal region in the rat. II. 
Morphogenesis during embryonic and early postnatal life. J Comp Neurol 190:115-134. Medline

Bekenstein JW, Lothman EW (1991) A comparison of the ontogeny of excitatory and inhibitory neurotransmission in the CA1 region and dentate gyrus of the rat hippocampal formation. Brain Res Dev Brain Res 63:237241. Medline

Ben-Ari Y, Khazipov R, Leinekugel X, Caillard O, Gaiarsa JL (1997) GABAA, NMDA and AMPA receptors: a developmentally regulated "ménage à trois". Trends Neurosci 20:523-529. Medline

Birrell JM, Brown VJ (2000) Medial frontal cortex mediates perceptual attentional set shifting in the rat. J Neurosci 20:4320-4324. Medline

Bliss TV, Chung SH, Stirling RV (1974) Proceedings: structural and functional development of the mossy fibre system in the hippocampus of the post-natal rat. J Physiol 239:92P-94P. Medline

Bronstein PM, Spear NE (1972) Acquisition of a spatial discrimination by rats as a function of age. J Comp Physiol Psychol 78:208-212. CrossRef Medline

Chavez-Noriega LE, Stevens CF (1992) Modulation of synaptic efficacy in field CA1 of the rat hippocampus by forskolin. Brain Res 574:85-92. CrossRef Medline

Choi S, Klingauf J, Tsien RW (2000) Postfusional regulation of cleft glutamate concentration during LTP at 'silent synapses'. Nat Neurosci 3:330336. CrossRef Medline

Costa PF, Santos AI, Ribiero MA (1994) Potassium currents in acutely isolated maturing rat hippocampal CA1 neurones. Brain Res Dev Brain Res 83:216-223. Medline

Douglas RJ (1972) Pavlovian conditioning and the brain. In: Inhibition and learning (Boakes RA, Halliday MS, eds), 529-553. New York: Academic.

Douglas RJ, Peterson JJ, Douglas DP (1973) The ontogeny of a hippocampus-dependent response in two rodent species. Behav Biol 8:27-37. CrossRef Medline

Dumas TC (2004) Early eyelid opening enhances spontaneous alternation and accelerates the development of perforant path synaptic strength in the hippocampus of juvenile rats. Dev Psychobiol 45:1-9. CrossRef Medline

Dumas TC (2005a) Late postnatal maturation of excitatory synaptic transmission permits the expression of adult-like hippocampal-dependent behaviors. Hippocampus 15:562-578. CrossRef Medline

Dumas TC (2005b) Developmental regulation of cognitive abilities: Modified composition of a molecular switch turns on associative learning. Prog Neurobiol 76:189-211. CrossRef Medline

Dumas TC (2012) Postnatal alterations in induction threshold and expression magnitude of long-term potentiation and long-term depression at hippocampal synapses. Hippocampus 22:188-199. CrossRef Medline

Dumas TC, Foster TC (1995) Developmental increase in CA3-CA1 presynaptic function in the hippocampal slice. J Neurophysiol 73:1821-1828. Medline

Durand GM, Zukin RS (1993) Developmental regulation of mRNAs encoding rat brain kainate/AMPA receptors: a northern analysis study. J Neurochem 61:2239-2246. CrossRef Medline

Durand GM, Kovalchuk Y, Konnerth A (1996) Long-term potentiation and functional synapse induction in developing hippocampus. Nature 381: 71-75. CrossRef Medline

Fukaya M, Yamazaki M, Sakimura K, Watanabe M (2005) Spatial diversity in gene expression for VDCCg subunit family in developing and adult mouse brains. Neurosci Res 53:376-383. CrossRef Medline

Green RJ, Stanton ME (1989) Differential ontogeny of working memory and reference memory in the rat. Behav Neurosci 103:98-105. CrossRef Medline

Harris KM, Teyler TJ (1983) Evidence for late development of inhibition in area CA1 of the rat hippocampus. Brain Res 268:339-343. CrossRef Medline

Hayman RM, Jeffery KJ (2008) How heterogeneous place cell responding arises from homogeneous grids-a contextual gating hypothesis. Hippocampus 18:1301-1313. CrossRef Medline

Hsia AY, Malenka RC, Nicoll RA (1998) Development of excitatory circuitry in the hippocampus. J Neurophysiol 79:2013-2024. Medline

$\mathrm{Hu}$ D, Amsel A (1995) A simple test of the vicarious trial-and-error hypothesis of hippocampal function. Proc Natl Acad Sci U S A 92:5506-5509. Medline

Hussain RJ, Carpenter DO (2001) Development of synaptic responses and plasticity at the SC-CA1 and MF-CA3 synapses in rat hippocampus. Cell Mol Neurobiol 21:357-368. Medline
Huttenlocher J (2008) Coding location: the view from toddler studies. Am Psychol 63:641-648. CrossRef Medline

Jackson AC, Nicoll RA (2011) The expanding social network of ionotropic glutamate receptors: TARPs and other transmembrane auxiliary subunits. Neuron 70:178-199. CrossRef Medline

Kentros C, Hargreaves E, Hawkins RD, Kandel ER, Shapiro M, Muller RV (1998) Abolition of long-term stability of new hippocampal place cell maps by NMDA receptor blockade. Science 280:2121-2126. CrossRef Medline

Kudryashov IE, Kudryashova IV (2001) Ontogeny of synaptic transmission in the rat hippocampus. Brain Res 892:263-268. CrossRef Medline

Langston RF, Ainge JA, Couey JJ, Canto CB, Bjerknes TL, Witter MP, Moser EI, Moser MB (2010) Development of the spatial representation system in the rat. Science 328:1576-1580. CrossRef Medline

Lauri SE, Palmer M, Segerstrale M, Vesikansa A, Taira T, Collingridge GL (2007) Presynaptic mechanisms involved in the expression of STP and LTP at CA1 synapses in the hippocampus. Neuropharmacology 52:1-11. CrossRef Medline

Liao D, Zhang X, O'Brien R, Ehlers MD, Huganir RL (1999) Regulation of morphological postsynaptic silent synapses in developing hippocampal neurons. Nat Neurosci 2:37-43. CrossRef Medline

Martin LJ, Furuta A, Blackstone CD (1998) Ampa receptor protein in developing rat brain: glutamate receptor-1 expression and localization change at regional, cellular and subcellular levels with maturation. Neuroscience 83:917-928. CrossRef Medline

Montgomery KE, Kessler M, Arai AC (2009) Modulation of agonist binding to AMPA receptors by 1-(1,4-benzodioxan-6-ylcarbonyl)piperidine (CX546): differential effects across brain regions and GluA1-4/transmembrane AMPA receptor regulatory protein combinations. J Pharmacol Exp Ther 331:965-974. CrossRef Medline

Morris RG, Moser EI, Riedel G, Martin SJ, Sandin J, Day M, O'Carroll C (2003) Elements of a neurobiological theory of the hippocampus: the role of activity-dependent synaptic plasticity in memory. Philos Trans R Soc Lond B Biol Sci 358:773-786. CrossRef Medline

Muenzinger KF (1938) Vicarious trial and error at a point of choice: I. A general survey of its relation to learning efficiency. Journal of Genetic Psychology 53:75-86.

Papale AE, Stott JJ, Powell NJ, Regier PS, Redish AD (2012) Interactions between deliberation and delay-discounting in rats. Cogn Affect Behav Neurosci 12:513-526. CrossRef Medline

Renger JJ, Egles C, Liu G (2001) A developmental switch in neurotransmitter flux enhances synaptic efficacy by AMPA receptor activation. Neuron 29:469-484. CrossRef Medline

Ritter LM, Vazquez DM, Meador-Woodruff JH (2002) Ontogeny of ionotropic glutamate receptor subunit expression in the rat hippocampus. Brain Res Dev Brain Res 139:227-236. CrossRef Medline

Rogers CJ, Hunter BE (1992) Chronic ethanol treatment reduces inhibition in CA1 neurons of the rat hippocampus. Brain Res Bull 28:587592. CrossRef Medline

Rudy JW, Stadler-Morris S, Albert P (1987) Ontogeny of spatial navigation behaviors in the rat: dissociation of "proximal"- and "distal"-cue-based behaviors. Behav Neurosci 101:62-73. CrossRef Medline

Sagar SM, Sharp FR (1993) Early response genes as markers of neuronal activity and growth factor action. Adv Neurol 59:273-284. Medline

Schenk F (1985) Development of place navigation in rats from weaning to puberty. Behav Neural Biol 43:69-85. CrossRef Medline

Scott RC, Richard GR, Holmes GL, Lenck-Santini PP (2011) Maturational dynamics of hippocampal place cells in immature rats. Hippocampus 21:347-353. CrossRef Medline

Shah AA, Sjovold T, Treit D (2004) Inactivation of the medial prefrontal cortex with the $\mathrm{GABA}_{\mathrm{A}}$ receptor agonist muscimol increases open-arm activity in the elevated plus-maze and attenuates shock-probe burying in rats. Brain Res 1028:112-115. CrossRef Medline

Spigelman I, Zhang L, Carlen PL (1992) Patch-clamp study of postnatal development of CA1 neurons in rat hippocampal slices: membrane excitability and $\mathrm{K}+$ currents. J Neurophysiol 68:55-69. Medline

Stella F, Treves A (2011) Associative memory storage and retrieval: involvement of theta oscillations in hippocampal information processing. Neural Plast. Article ID 683961.

Suzuki E, Kessler M, Arai AC (2008) The fast kinetics of AMPA GluR3 receptors is selectively modulated by the TARPs $\gamma 4$ and $\gamma 8$. Mol Cell Neurosci 38:117-123. CrossRef Medline 
Tischmeyer W, Kaczmarek L, Strauss M, Jork R, Matthies H (1990) Accumulation of c-fos mRNA in rat hippocampus during acquisition of a brightness discrimination. Behav Neural Biol 54:165-171. CrossRef Medline

Tolman EC (1938) The determiners of behavior at a choice point. Psychological Review 46:318-336.

Tomita S, Chen L, Kawasaki Y, Petralia RS, Wenthold RJ, Nicoll RA, Bredt DS (2003) Functional studies and distribution define a family of transmembrane AMPA receptor regulatory proteins. J Cell Biol 161: 805-816. CrossRef Medline

Velísek L, Moshé SL, Stanton PK (1993) Age dependence of homosynaptic non-NMDA-mediated long-term depression in field CA1 of rat hippocampal slices. Brain Res Dev Brain Res 75:253-260. CrossRef Medline

Walf AA, Frye CA (2007) The use of the elevated plus maze as an assay of anxiety-related behavior in rodents. Nat Protoc 2:322-328. CrossRef Medline

Wall PM, Messier C (2000) U-69,593 microinjection in the infralimbic cortex reduces anxiety and enhances spontaneous alternation memory in mice. Brain Res 856:259-280. CrossRef Medline

Wang DS, Inokuchi H, Tanaka E, Isagai T, Li J-S, Higashi H (2002) Postna- tal changes in the overall postsynaptic currents evoked in CA1 pyramidal neurons of the rat hippocampus. Life Sci 72:341-353. CrossRef Medline

Waters NS, Klintsova AY, Foster TC (1997) Insensitivity of the hippocampus to environmental stimulation during postnatal development. J Neurosci 17:7967-7973. Medline

Watson DJ, Stanton ME (2009) Medial prefrontal administration of MK801 impairs T-maze discrimination reversal learning in weanling rats. Behav Brain Res 205:57-66. CrossRef Medline

Wills TJ, Cacucci F, Burgess N, O'Keefe J (2010) Development the hippocampal cognitive map in preweanling rats. Science 328:1487-1488. CrossRef Medline

Xia YF, Arai AC (2005) AMPA receptor modulators have different impact on hippocampal pyramidal cells and interneurons. Neuroscience 135:555-567. CrossRef Medline

Xia YF, Kessler M, Arai AC (2005) Positive alpha-amino-3-hydroxy-5methyl-4-isoxazolepropionic acid (AMPA) receptor modulators have different impact on synaptic transmission in the thalamus and hippocampus. J Pharmacol Exp Ther 313:277-285. CrossRef Medline

Zimmer J, Haug FM (1978) Laminar differentiation of the hippocampus, fascia dentata and subiculum in developing rats, observed with the Timm sulphide silver method. J Comp Neurol 179:581-617. CrossRef Medline 